\title{
A 13-year study of dissolved organic carbon in rainwater of an agro-industrial region of São Paulo state (Brazil) heavily impacted by biomass burning
}

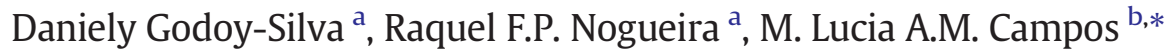 \\ a Univ Estadual Paulista (UNESP), Departamento de Química Analítica, Instituto de Química, 14800-060 Araraquara, SP, Brazil \\ ${ }^{\mathrm{b}}$ Universidade de São Paulo (USP), Departamento de Química, Faculdade de Filosofia, Ciências e Letras de Ribeirão Preto, 14040-901 Ribeirão Preto, SP, Brazil
}

\section{H I G H L I G H T S}

- Biomass burning was the dominant source of DOC in rainwater.

- The wet deposition flux of DOC was $44 \%$ higher than the published world average.

- Volatile dissolved organic carbon comprised up to $53 \%$ of the DOC in rainwater.

- DOC in rainwater appeared to be mostly labile and rapidly bioavailable.

\section{G R A P H I C A L A B S T R A C T}
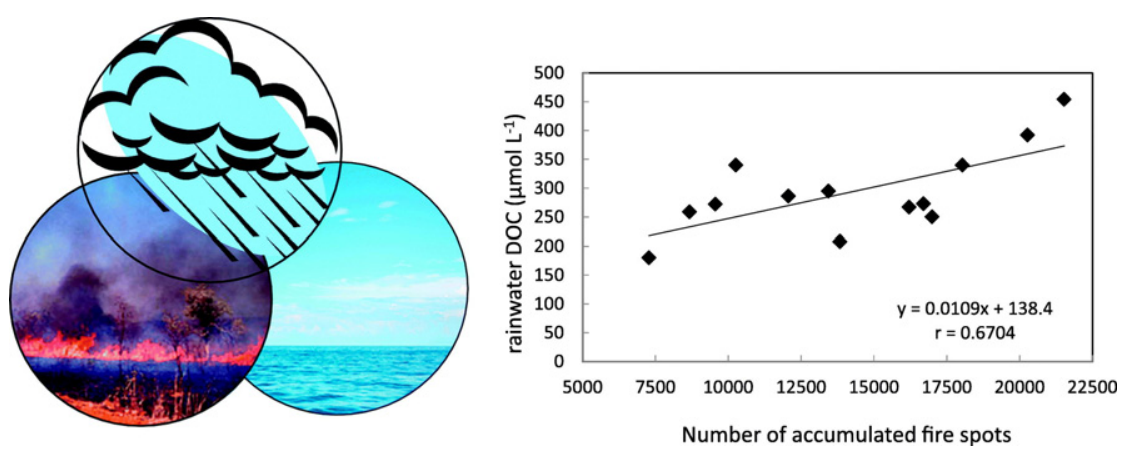

A B S T R A C T

This work presents the first comprehensive study of DOC in rainwater in a tropical agro-industrial region in central São Paulo State. The DOC concentrations ranged from 15 to $4992 \mu \mathrm{mol} \mathrm{C} \mathrm{L}{ }^{-1}$, with an overall volume weighted mean (VWM) of $288 \pm 17 \mu \mathrm{mol} \mathrm{C} \mathrm{L}{ }^{-1}(\mathrm{n}=881)$. The number of fire spots accumulated within each year of this study was positively correlated to the VWM concentration of DOC in rainwater. During the whole study period, higher VWM DOC concentrations were found during the dry months, despite the phasing out of agricultural fires in sugar cane plantations. The evidence suggested that inputs of atmospheric soluble organic carbon from biomass burning exceeded those from vehicular fuel combustion and biogenic sources. In most cases, dilution of DOC according to precipitation volume was minimal, showing that in-cloud processes were dominant for this species. In contrast, most of the volatile dissolved organic carbon (VDOC) appeared to be removed from the atmosphere in the first milliliter or so of rain, showing a dominance of below-cloud scavenging. VDOC contributed a significant fraction of the DOC for $62 \%$ of the samples analyzed, ranging from 5.1 to 488 $\mu \mathrm{mol} \mathrm{C} \mathrm{L}^{-1}(\mathrm{n}=552)$. The average wet deposition flux of DOC was $49 \mathrm{~kg} \mathrm{C} \mathrm{ha}^{-1} \mathrm{yr}^{-1}$, with VDOC accounting for $10 \%$ of the total. This dissolved carbon flux is higher than the estimated world average ( $34 \mathrm{~kg} \mathrm{C} \mathrm{ha}^{-1} \mathrm{yr}^{-1}$ ). The DOC in the rainwater was mostly labile ( $75 \%$ on average) and rapidly bioavailable (within days to weeks), in contrast to refractory dissolved carbon found in rainwater from regions where fossil fuel combustion is the dominant source. The findings of this work indicate that biomass burning can lead to important atmospheric inputs of readily available organic matter to land and to the open ocean.

(c) 2017 Elsevier B.V. All rights reserved.

\footnotetext{
* Corresponding author.

E-mail address: lcampos@ffclrp.usp.br (M.L.A.M. Campos).
} 


\section{Introduction}

The atmosphere is an important reservoir of carbon that plays a key role in global radiative forcing. Atmospheric organic carbon (OC) originates from multiple sources. On a global scale, biogenic emissions are the most significant source category, consisting mainly of volatile organic carbon (VOC) emitted by vegetation (dominated by isoprene and monoterpenes), together with particles such as pollen, fungal spores, and plant debris released into the atmosphere (Kanakidou et al., 2012).

Regionally, anthropogenic emissions of OC due to fossil fuel combustion can overwhelm natural sources, especially in highly urbanized regions (Wang et al., 2016). Biomass burning, as either a natural (10\%) or intentional (90\%) process, is an important source of atmospheric OC (including volatile species), especially in the tropics (Iavorivska et al., 2016). In such regions, fire is intensively used for deforestation, land clearance for temporary cultivations, and removal of dry vegetation to improve productivity. It has been estimated that globally, wildfires contribute to an amount of carbon equivalent to about $20 \%$ of the fossil fuel carbon emitted to the atmosphere, although the increasing demand for food, together with changes in the global climate, may increase the contribution of biomass burning in the near future (Keywood et al., 2013).

Since the early 1990s, emissions of gases and particles to the atmosphere due to biomass burning have been linked to ozone formation, changes in tropospheric chemistry, and impacts on climate (Crutzen and Andreae, 1990). In the past decades, numerous studies have shown that primary smoke particles and secondary organic aerosols affect the number of cloud condensation nuclei, cloud droplet size, and precipitation (Kanakidou et al., 2012, and references therein). Clouds are important in controlling the Earth's heat balance, so largescale changes in their properties are likely to strongly affect the climate. Secondary particles can be formed by condensation of VOC molecules that contain multiple functional groups. The primary VOC compounds emitted can also be oxidized during photochemical processes in the atmosphere, forming less volatile species that are subsequently transformed into solid-phase particles (Hallquist et al., 2009).

Kanakidou et al. (2012), using a tridimensional global model, estimated that annually $1108 \mathrm{Tg} C$ (values reported in the literature range

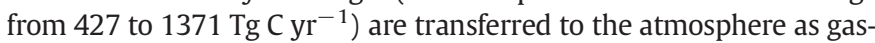
eous and particulate OC. Approximately $90 \%$ of this carbon is in the form of VOC and $10 \%$ is in the particulate organic form. Atmospheric OC species are removed from this compartment by means of wet precipitation (60\%) and dry deposition (40\%). Of the total amount of OC

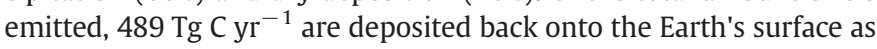
soluble OC (dissolved organic carbon - DOC), leading to a deposition of about $50 \%$ onto land and $50 \%$ into the ocean. The remaining OC emitted is transformed in the atmosphere into secondary organic products, carbon monoxide, and ultimately carbon dioxide.

In an earlier study, Raymond (2005) suggested that the net transfer of continental $\mathrm{OC}$ to the ocean could be close to zero, considering the exchange fluxes between the two ecosystems. However, this calculation could underestimate the terrestrial transfer of organic carbon, because it assumed an average concentration of dissolved organic carbon (DOC) in continental rainwater of $90 \mu \mathrm{mol} \mathrm{C} \mathrm{L}-1$, which is well below the global continental average of $239 \mu \mathrm{mol} \mathrm{C} \mathrm{L}{ }^{-1}$, estimated by Iavorivska et al. (2016).

The concentration of DOC in rainwater can be highly variable, both spatially and temporally, and biomass burning emissions are especially associated with the southern hemisphere, where the paucity of data on rainwater DOC is notorious. Several studies have noted that global estimates of the transfer of atmospheric organic carbon to the Earth's surface have large uncertainties, due to a lack of knowledge concerning DOC in precipitation (Iavorivska et al., 2016, and references therein). Terrestrial inputs of bioavailable organic carbon to fuel oceanic primary productivity are a subject of increasing interest (Hansell et al., 2004). However, in order to improve understanding of the role of wet deposition of DOC to terrestrial and marine ecosystems, it is essential to investigate the sources, concentrations, and reactivity of the organic matter present in rainwater, especially in the southern hemisphere.

This study was conducted in an agro-industrial region of São Paulo State (Brazil), where sugar cane plantation and processing is the main economic activity. Brazil is the world leader in sugar cane production, and about half of the total is used to produce ethanol fuel (UNICA, 2016; FAO, 2017). Vehicular ethanol fuel has been produced in Brazil since the 1970s and is used either directly or as a gasoline additive (23-28\%, v/v; Anderson, 2009). Since 2013, approximately $88 \%$ of all light duty vehicles in Brazil have been produced with dual-fuel technology, enabling the use of any proportion of gasoline and ethanol. The high internal and external demand for ethanol fuel has resulted in a doubling of the area planted with sugar cane in Brazil in the past 10 years or so, reaching over 10 million ha in 2016 (IBGE, 2016).

Prior to 2006, sugar cane harvesting was performed exclusively using manual labor, requiring burning of the plant foliage before cutting in order to protect workers from injuries and increase productivity. Subsequently, a mechanized process, which does not require the use of fire, has progressively substituted manual harvesting, reaching about $91 \%$ of the planted area in São Paulo State in 2016 (SMA, 2016). It is important to point out that the law that imposes phasing-out of manual harvesting only applies to São Paulo State, which accounts for around 50\% of the country's sugar cane production. Remote sensing data show that fire in rural regions of Brazil and in the savanna biome is still very common, either for expansion of agriculture and pasture, or for removal of waste and renewal of agricultural areas (INPE, 2017).

In the past decade, the study region has experienced a major shift in agricultural practices, while at the same time there has been important regional economic growth, resulting in increases in the number of inhabitants and the size of the vehicle fleet. The temporally-resolved assessment of DOC in rainwater can provide important information about the sources of carbon emissions to the atmosphere, as well as possible shifts over time.

The aims of this work were to identify the main regional sources of organic carbon emissions, calculate the wet deposition fluxes of dissolved organic carbon, and evaluate its bioavailability. This is the first long-term assessment of DOC and volatile dissolved organic carbon (VDOC) in rainwater from a Brazilian region where fire is a common practice in agricultural management. The use of fire in farming is part of the culture of several countries of Latin America and Africa, so the data provided here can serve as a basis for improving regional and global carbon cycle models. Keywood et al. (2013) drew attention to the fact that extreme weather events associated with a warming climate are likely to increase wildfires (such as those seen in the western United States, Australia, and Portugal), so it is imperative to improve understanding of the impacts of biomass burning on global atmospheric chemistry.

\section{Experimental}

\subsection{Collection sites and meteorological information}

The rainwater sampling sites were located on the UNESP and USP campuses in the municipalities of Araraquara (AQA) $\left(21^{\circ} 47^{\prime} 37^{\prime \prime} \mathrm{S}\right.$, $\left.48^{\circ} 10^{\prime} 52^{\prime \prime} \mathrm{W}\right)$ and Ribeirão Preto (RP) $\left(21^{\circ} 10^{\prime} 42^{\prime \prime} \mathrm{S}, 47^{\circ} 48^{\prime} 24^{\prime \prime} \mathrm{W}\right)$, respectively. Both sites were around $1 \mathrm{~km}$ distant from extensive sugar cane plantations (Fig. 1).

AQA and RP were chosen for this study because they are both located within the sugar cane belt of the State and their main economic activities are based on sugar cane plantation and processing. Although they have different populations, which could influence organic carbon emissions (AQA has 228,000 inhabitants and RP has 674,000; IBGE, 2016), as this time series evolved, it became clear there were no significant differences between the rainwater DOC concentration ranges or averages for the two sites. Nevertheless, sample collections were maintained at both sites in order to obtain a larger data set and enable a more 

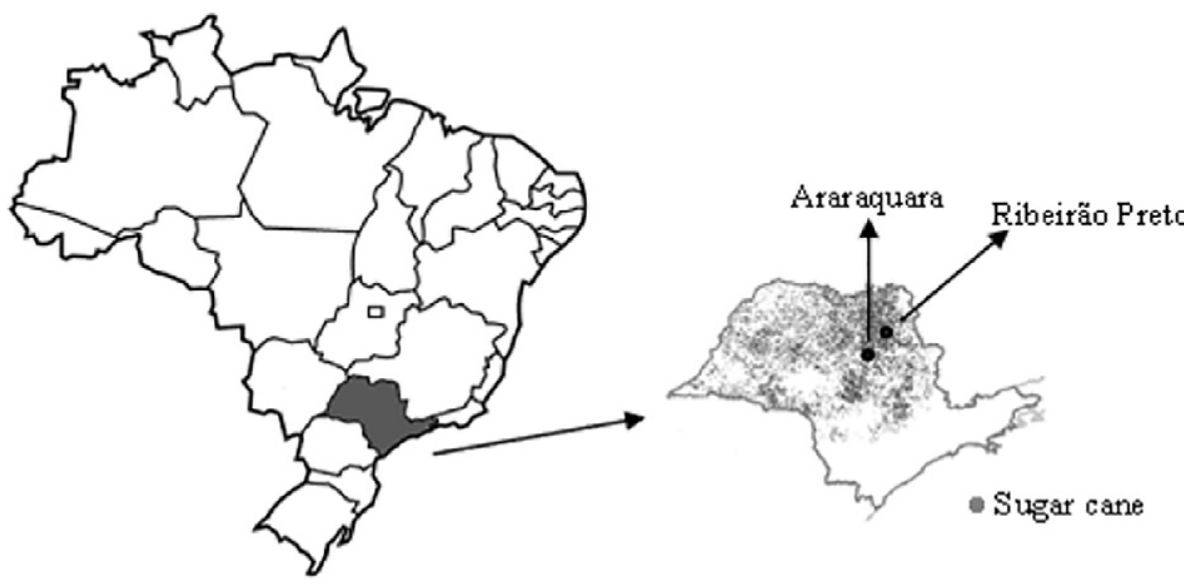

Fig. 1. Map of Brazil with a zoom showing the areas planted with sugar cane in São Paulo State and the sampling locations in Ribeirão Preto (RP) and Araraquara (AQA).

comprehensive study. The two municipalities have a typical tropical climate with a dry season from April to September, and a rainy (warmer) season from October to March. There is a small average temperature gradient between summer and winter $\left(\sim 5^{\circ} \mathrm{C}\right)$. The sugar cane harvest period usually extends from April to November each year, but harvesting is most intense between July and October, coinciding with the driest months. Annual average rainfall depths are very similar at the two locations: $1430 \mathrm{~mm}$ (AQA) and $1422 \mathrm{~mm}(\mathrm{RP})$, with approximately 80\% of the rain volume falling during the rainy season (CEPAGRI, 2016).

\subsection{Sampling}

Rainwater samples were collected from July 2004 to December 2016 ( $\mathrm{n}=881$ ), using a wet-only automatic collector. The collector was maintained closed in the field and would only open when the first drops of rain reached the sensor. When the event finished, the sensor's heating system provided rapid evaporation of the remaining drops on its surface, automatically closing the funnel. On some occasions ( $\mathrm{n}=$ 38), an additional sampling system was set up in parallel in the field and the collection bottle was withdrawn after the first $1 \mathrm{~mm}$ or so of rainwater. Samples were removed from the sites immediately after precipitation events or in the early morning if the rain event occurred overnight.

The glass bottle and funnel used to collect the rainwater were replaced by a clean set after each event, and before use were decontaminated with Fenton solution $\left(1.0 \mathrm{mmol} \mathrm{L}^{-1} \mathrm{Fe}^{2+}\right.$ and $100 \mathrm{mmol} \mathrm{L}^{-1} \mathrm{H}_{2} \mathrm{O}_{2}$ ), as described by Campos et al. (2007). The rainwater was filtered immediately after collection and stored at $5{ }^{\circ} \mathrm{C}$ for no longer than 3-4 days. Until 2014, filtration was performed using 0.7 $\mu \mathrm{m}$ glass fiber membranes (Millipore) that had been previously calcined at $450{ }^{\circ} \mathrm{C}$ for $6 \mathrm{~h}$. Subsequently, filtration was performed using polyethersulfone membranes $(0.2 \mu \mathrm{m})$ to enable different types of analyses. DOC concentrations were measured in 13 samples after filtration using both membranes, and the results were not statistically different ( $t$-test, $\mathrm{P}=0.05)$. The membrane cleaning procedure consisted of passing $\sim 30 \mathrm{~mL}$ of ultrapure water and $\sim 20 \mathrm{~mL}$ of rainwater, which were discarded. The membrane blank values were periodically checked, and no significant DOC leaching was observed after the cleaning process.

\subsection{Chemical analysis}

The concentrations of different forms of dissolved carbon in rainwater were determined by high temperature combustion, using a Shimadzu TOC-5000A total organic carbon analyzer with a normal sensitivity catalyst. Details of the determination, including blank checks, limits of detection, and precision can be found in Campos et al. (2007). Briefly, the DOC determination consisted of two steps, with quantification of total carbon (TC) followed by inorganic carbon (IC). In the present work, particulate carbon was removed by filtration, so TC corresponded to the total dissolved carbon. TC was measured using high temperature catalytic oxidation, with conversion of all the organic matter and inorganic carbon to $\mathrm{CO}_{2}$. The determination of IC involved acidifying and purging a new sample aliquot, without the catalytic oxidation step. Although volatile organic carbon was eliminated during this purging procedure, only $\mathrm{CO}_{2}$ could be detected and measured by the infrared sensor. Since the samples were previously filtered, the difference between TC and IC corresponded to the dissolved organic carbon fraction (DOC).

VDOC was routinely measured from 2008 onwards $(n=552)$. For the determination of this species, another sample aliquot was firstly acidified and purged during 10 min to allow all the inorganic and volatile carbon to be lost to the atmosphere. The remaining non-purgeable organic carbon (NPOC) was detected by injecting an aliquot into the combustion tube. VDOC was then quantified as the difference between DOC and NPOC. Several studies have used only this last measurement and assumed that NPOC was equal to DOC, which may not always be true, especially for low volumes of rain (Campos et al., 2007; Avery et al., 2009).

Individual aqueous standard solutions of ethanol, acetaldehyde, and formaldehyde were submitted to the purging system of the TOC equipment in order to measure the loss of volatile dissolved carbon species. The standard procedure for measurement of NPOC involves purging the sample for $10 \mathrm{~min}$ after acidification to $\mathrm{pH} 3$. However, in this study, longer purging times were used to evaluate whether there would be further removal of VDOC. The ethanol concentration was monitored by DOC and NPOC measurements, and the acetaldehyde and formaldehyde solutions were analyzed by high performance liquid chromatography (Mopper and Kieber, 1990). The equipment used was a Shimadzu LC 20AT Prominence, equipped with a diode array detector and a C-18 column (Gemini, $5 \mu \mathrm{m}, 150 \times 4.60 \mathrm{~mm}$, from Phenomex) maintained at $40{ }^{\circ} \mathrm{C}$. The mobile phase was a mixture of acetonitrile and water (45:55) at a flow rate of $1 \mathrm{~mL} \mathrm{~min}^{-1}$. The injection volume was $40 \mu \mathrm{L}$ and the wavelength of detection $360 \mathrm{~nm}$.

\subsection{Air mass trajectories and data treatment}

To evaluate the variability of the DOC concentrations according to wind direction, three-day air mass back-trajectories arriving at 100 , 500, and $1000 \mathrm{~m}$ above ground level (NOAA HYSPLIT, 2017) were used to classify the samples according to the quadrants N-E, S-E, S-W, and $\mathrm{N}-\mathrm{W}$. This evaluation was performed with all the data for samples collected from 2013 to 2016, when manual sugar cane harvesting in São Paulo State (preceded by fire) was reduced to $25-15 \%$. 
The mean values of DOC and the standard deviations in a given period were calculated using the volume weighted mean (VWM; Hu and Balasubramanian, 2003; Mullaugh et al., 2011). The VWM calculation considers the sum of the number of mols for a set of rain events and divides by the total rain depth of the corresponding period, hence accounting for the influence of rain depth within different seasons, years, and parts of the world. Deposition fluxes were calculated based on the VWM and the historical rainfall depths. Comparison of the means of different sets of samples employed two-tailed $t$-tests with a significant level of 95\% (Miller and Miller, 2010).

\subsection{Bioavailability}

The bioavailability of the organic carbon in the rainwater was evaluated by firstly measuring DOC and VDOC in a filtered aliquot shortly after the rain event. The remainder of the non-filtered sample was split into several $20 \mathrm{~mL}$ aliquots, which were stored in amber bottles in the dark, at room temperature $\left(\sim 25^{\circ} \mathrm{C}\right)$, for up to 36 days. Each aliquot retrieved was filtered $(0.2 \mu \mathrm{m})$ prior to analysis of DOC and VDOC.

\section{Results and discussion}

\subsection{Dissolved organic carbon in rainwater}

The DOC concentrations in a total of 881 rainwater samples spanned 3 orders of magnitude, from 15 to $4992 \mu \mathrm{mol} \mathrm{C} \mathrm{L}^{-1}$, with the highest values found during the driest months of the year (Fig. 2). The overall volume weighted mean (VWM) concentration and standard deviation for the whole period was $288 \pm 17 \mu \mathrm{mol} \mathrm{C} \mathrm{L}{ }^{-1}$. This value is above the weighted average DOC concentration reported for the Amazon region (159 $\mu \mathrm{mol} \mathrm{C} \mathrm{L}{ }^{-1}$; Williams et al., 1997) and above the estimated global mean of $239 \mu \mathrm{mol} \mathrm{C} \mathrm{L}{ }^{-1}$ (Iavorivska et al., 2016).

The number of dry days before the rain event had no correlation with the DOC concentration. For instance, one of the highest peaks of DOC ( $4026 \mu \mathrm{mol} \mathrm{C} \mathrm{L}{ }^{-1}$; 02/Oct/2011) was preceded by 11 days of drought, while another event of the same magnitude $(7.1 \mathrm{~mm} ; 19 /$ Sep/2012) was preceded by 62 dry days, and the DOC concentration was about 3 times lower $\left(1419 \mu \mathrm{mol} \mathrm{C} \mathrm{L}{ }^{-1}\right)$. There was also no linear correlation between rainfall amount and DOC concentration, indicating an irregular major source of organic carbon (as will be discussed below). Considering a narrow precipitation range from 6.6 to $7.1 \mathrm{~mm}$ (a typical local rain amount), the variability of the DOC concentrations for the 16 samples spanned two orders of magnitude, with values from 28 to $4026 \mu \mathrm{mol} \mathrm{C} \mathrm{L}-1$.

Despite the decrease in sugar cane burning since 2006, the yearly DOC VWM values did not show any clear trend over the years, with

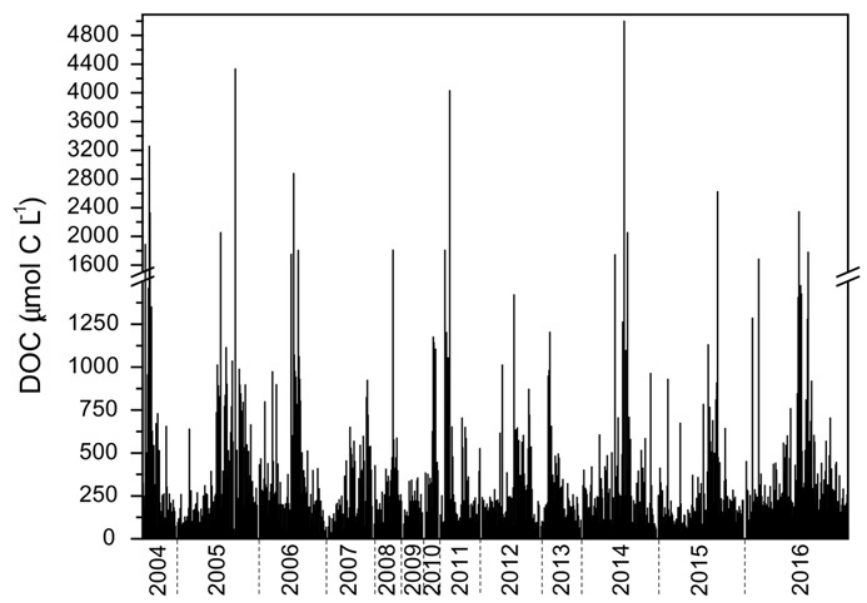

Fig. 2. DOC concentrations in rainwater samples collected from July 2004 to December $2016(n=881)$.

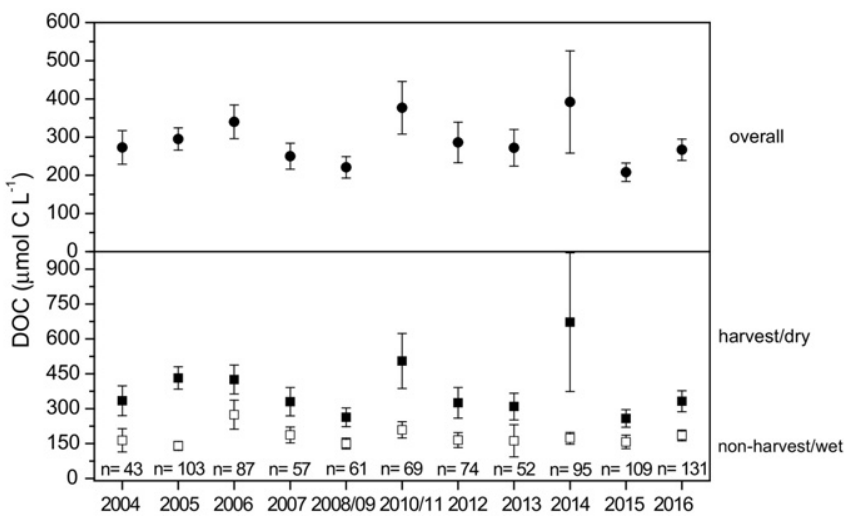

Fig. 3. Annual or biannual VWM DOC concentrations in rainwater samples. Typically, the harvest period was from April to November and the non-harvest period was from December to March. The number of samples (n) for each period is given in the graph.

the coefficient of variation for both seasons ranging from 11 to $44 \%$ (Fig. 3). Moreover, a significant difference between dry/harvest and wet/non-harvest periods was maintained for the whole time series $(t$ test, $\mathrm{P}=0.05)$. Considering the historical rainfall and the weighted mean concentration for each season, the estimated deposition fluxes were $2.5 \mathrm{~g} \mathrm{C} \mathrm{m}^{-2}$ in the harvest/dry period and $1.9 \mathrm{~g} \mathrm{C} \mathrm{m}^{-2}$ in the non-harvest/wet period. These fluxes showed that despite the lower precipitation amount (38\%) during the harvest/dry period, the inputs of organic carbon resulted in significant fluxes of dissolved carbon during this season.

Bordering the northern part of São Paulo State is the Savanna biome that often experiences fire (natural and manmade), especially for the expansion of cultivations (including sugar cane) or pasture, adding significant amounts of organic carbon to the atmosphere (Ciglasch et al., 2004; Boian and Kirchhoff, 2006). In 2015, the area of Savanna burnt was $323,496 \mathrm{~km}^{2}$, and the States bordering São Paulo (Goiás, Mato Grosso do Sul, and Minas Gerais) together had 22,795 fire spots detected (reference satellite; INPE, 2017).

The fact that many fire spots were still detected in the study region can explain the maintenance of the seasonal variation during the whole study period (Figs. 3 and 4). The overall DOC VWM concentration found for each year showed a significant correlation $(t$-test, $P=0.05)$ with the number of fire spots detected in the same year (reference satellite; INPE, 2017). The fire spots were calculated for the area defined by a radius of $600 \mathrm{~km}$, centered at Ribeirão Preto, corresponding to a wind speed of $8.3 \mathrm{~km} \mathrm{~h}^{-1}$ (typical in this region) during a 3-day period. The significant correlation between DOC in rainwater and the number of fire spots provides further evidence suggesting substantial emissions

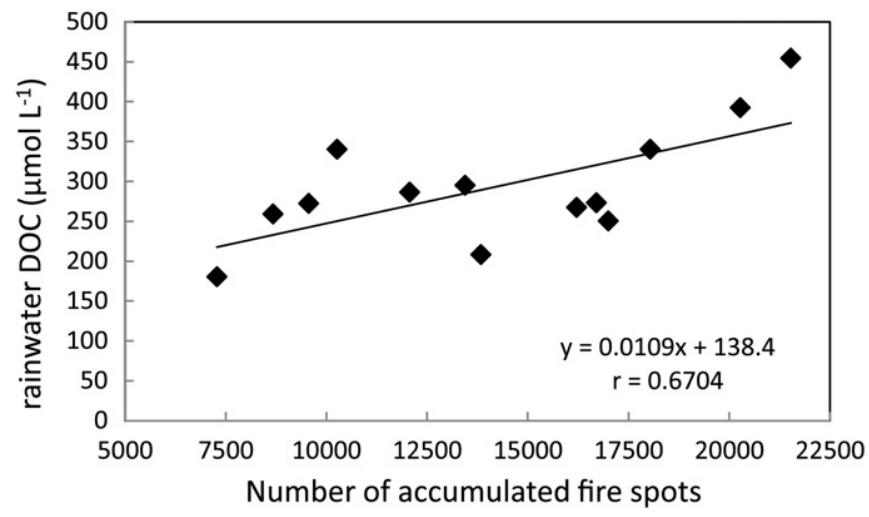

Fig. 4. DOC concentrations in rainwater according to the number of fire spots accumulated per year within an area defined by a radius of $600 \mathrm{~km}$, centered at Ribeirão Preto, from 2004 to 2016. 

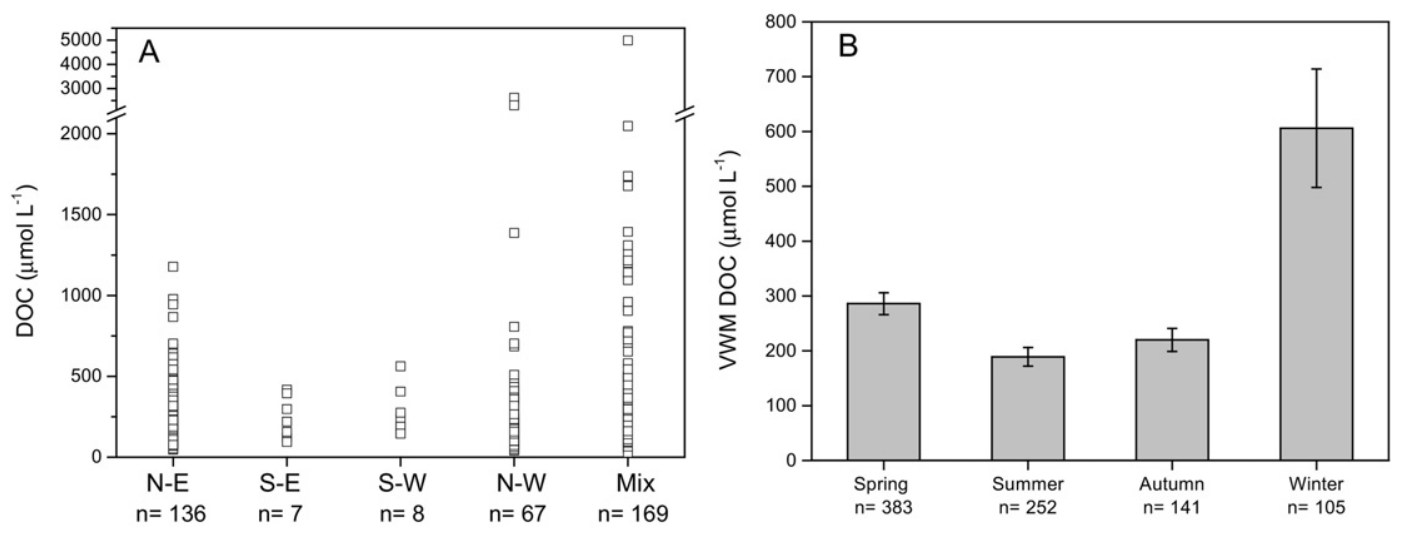

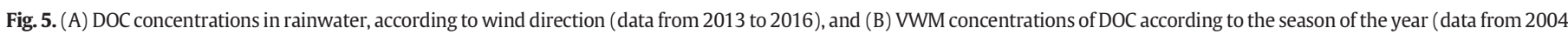
to 2016). The number of samples ( $\mathrm{n}$ ) is given in the graph.

of soluble organic carbon from agricultural burning and wildfires. The great influence of biomass burning on the chemical composition of the troposphere in the study region has been previously recognized by our group, based on measurements of levoglucosan (a specific biomass burning tracer) in atmospheric particulate matter (Urban et al., 2012, 2016). Additionally, rural fires have been identified as one of the most important factors affecting the levels of dissolved major ions in rainwater, as well as potassium concentrations in fine aerosol (Coelho et al., 2011; Souza et al., 2017).

Besides vegetation burning in the field, another important source of organic carbon emissions in the study region is the combustion of biomass residue (bagasse) formed after crushing the sugar cane. This material is used by the industry to fuel sugar cane and orange processing (the latter occurring mostly during the wet months). The bagasse surplus can be so plentiful that it is also used in thermoelectric power plants. This means that although sugar cane leaves are not burnt in the field, the cellulosic material present in the cane remains an important source of biomass burning emissions, which can explain the presence of specific chemical tracers (such as levoglucosan) in the atmosphere during the wet months (Urban et al., 2014, 2016).

In order to investigate possible spatial variability in the sources of emission of organic carbon, precipitation events from 2013 to 2016 were classified according to 3-day air mass back-trajectories. The prevailing winds were found to be from the N-E (35\%) and N-W (17\%) directions, corresponding to a more variable range of DOC concentrations, compared to the S-W and S-E wind directions, which were much less frequent ( 2\%; Fig. 5A). Southeasterly air masses passed over the largest and most industrialized cities of São Paulo State, which together have around 32 million inhabitants. Nonetheless, it appeared that inputs from vehicular and industrial sources were smaller, compared to the biomass burning inputs. Previous work in the study region showed that fossil fuel combustion tracers (such as fluoranthene and benzo(ghi)perylene) in atmospheric particulate matter presented no concentration trends during the year (Urban et al., 2016). In contrast, aerosol collected during the dry months was enriched in retene, a biomass burning tracer. These findings, added to the ones presented in this work, evidenced that emissions of soluble organic carbon from biomass burning overwhelmed those from fossil fuel combustion.

Biogenic emissions of organic carbon may be significant during periods of vegetation growth in countries with well-defined seasons (Kieber et al., 2002; Tsigaridis and Kanakidou, 2003). In the study region, insolation and temperature do not vary substantially during the year, and biogenic emissions would be expected to be higher during the summer months, due to greater water availability (Cepagri, 2016). Nevertheless, our data suggest that biogenic emissions were a minor source of organic carbon, since the lowest VWM concentration of DOC was found in the summer (wet) months (Fig. 5B). This corroborates previous findings by our group showing that concentrations of biomass burning sugar tracers (levoglucosan, mannosan, and galactosan) were twice as high in aerosol collected during the winter, compared to the summer. In contrast, no increases of sugar tracers of biological sources, such as arabitol and mannitol, were observed during the summer (Scaramboni et al., 2015; Urban et al., 2014).

\subsection{Volatile dissolved organic carbon in rainwater}

In this work, significant levels of $\operatorname{VDOC}\left(>5 \mu \mathrm{mol} \mathrm{C} \mathrm{L}{ }^{-1}\right)$ were found in 340 samples, corresponding to $62 \%$ of the total number of samples in which this species was analyzed $(n=552)$. VDOC concentrations ranged from 5.1 to $488 \mu \mathrm{mol} \mathrm{C} \mathrm{L}{ }^{-1}$, accounting for up to $53 \%$ of the total dissolved organic carbon present in the samples (Fig. 6). These results reinforced the previous findings by Campos et al. (2007) showing that non-purgeable organic carbon (NPOC) cannot always be expressed as DOC, which could result in substantial underestimation of the amount of dissolved carbon.

Similar to DOC, most of the volatile carbon concentrations above 100 $\mu \mathrm{mol} \mathrm{C} \mathrm{L}{ }^{-1}$ (19 out of 23 data points) were observed during the dry period, with rain depths for these events ranging from 0.5 to $28 \mathrm{~mm}$. The annual VWM VDOC concentration was $29 \pm 3 \mu \mathrm{mol} \mathrm{C} \mathrm{L}{ }^{-1}$, corresponding to a wet flux of $0.50 \mathrm{~g} \mathrm{C} \mathrm{m}^{-2} \mathrm{yr}^{-1}$, which accounts for $10 \%$ of the DOC flux. For the dry/harvest period, the concentration was 34 $\pm 4 \mu \mathrm{mol} \mathrm{C} \mathrm{L}{ }^{-1}(\mathrm{n}=213)$, which was significantly higher than for the wet/non-harvest period ( $20 \pm 2 \mu \mathrm{mol} \mathrm{C} \mathrm{L}{ }^{-1} ; \mathrm{n}=127$ ), indicating a significant contribution of volatile organic carbon from biomass burning ( $t$-test, $\mathrm{P}=0.05)$.

Hydrocarbons (mostly alkanes) have been found to be highly abundant in particulate matter from the same study region, especially during

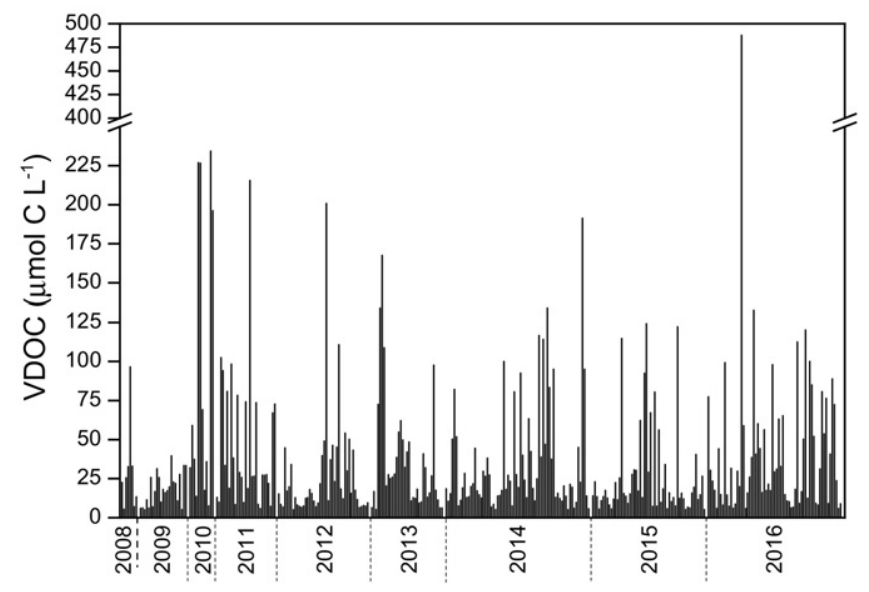

Fig. 6. VDOC concentrations in rainwater samples $(n=340)$. 
Table 1

Percentage removal of ethanol, formaldehyde, and acetaldehyde from standard solutions after acidification at $\mathrm{pH} 3$, using different purging times.

\begin{tabular}{llll}
\hline & $10 \min$ & $20 \mathrm{~min}$ & $40 \mathrm{~min}$ \\
\hline Ethanol $\left(100 \mu \mathrm{mol} \mathrm{L}^{-1}\right)$ & 3 & 14 & 14 \\
Formaldehyde $\left(0.2 \mu \mathrm{mol} \mathrm{L}^{-1}\right)$ & 6 & 8 & 12 \\
Acetaldehyde $\left(0.2 \mu \mathrm{mol} \mathrm{L}^{-1}\right)$ & 11 & 56 & 74
\end{tabular}

the dry months (Urban et al., 2016). Despite the nonpolar character of the compounds, the precipitation process may scavenge a proportion of these molecules into the aqueous phase, contributing to increasing the volatile organic carbon content of the rainwater. As mentioned above, there is substantial use of sugar cane bagasse as an industrial fuel, with the associated emissions being an important source of VDOC to the atmosphere (Coelho et al., 2008; Urban et al., 2014).

Emissions of volatile carbon from biological sources could be expected to be higher during summer, albeit at relatively low levels because the VDOC volume weighted average concentration for this period (20.1 $\mu \mathrm{mol} \mathrm{C} \mathrm{L}{ }^{-1}$ ) was less than half the value found for the winter seaSon $\left(57.2 \mu \mathrm{mol} \mathrm{C} \mathrm{L}{ }^{-1}\right)$.

\subsection{Oxygenated low molecular weight dissolved carbon}

In Brazil, vehicular ethanol is an important source of volatile carbon to the atmosphere, due to the extensive use of this fuel. As this species is highly soluble, it can be scavenged during rain events and contribute to the volatile fraction of the organic carbon content of rainwater (Giubbina et al., 2017; Félix et al., 2017). To date, no experimental tests have been performed to evaluate whether ethanol and correlated compounds derived from vehicular emissions would be identified as volatile carbon by the analytical methods commonly used.

The standard procedure involving purging for $10 \mathrm{~min}$ resulted in removal of only $3 \%$ of ethanol, $6 \%$ of formaldehyde, and $11 \%$ of acetaldehyde (Table 1 ). After purging for $40 \mathrm{~min}$, only acetaldehyde showed substantial removal from the solution (74\% removal). The formation of hydrogen bonds between ethanol and water makes it difficult to volatilize the alcohol. In aqueous solution, $99.9 \%$ of formaldehyde is in the form of a diol $\left(\mathrm{CH}_{2}(\mathrm{OH})_{2}\right)$, due to its high hydrolysis equilibrium constant $\left(K_{h}=2300\right)$, so a small loss of this compound was expected during the purging procedure (Carey, 1983). In the case of acetaldehyde, an acidic medium favors its hydration, contributing to its incomplete removal (Carey, 1983). Hence, the volatile carbon detected in the samples studied could not be attributed to direct biofuel emissions. The sum of the carbon content corresponding to the average concentrations of ethanol, methanol, acetone, acetaldehyde, and formaldehyde in rainwater, reported in published work, was calculated to be $\sim 24 \mu \mathrm{mol} \mathrm{C} \mathrm{L}{ }^{-1}$, which is a substantial quantity, considering the average VDOC concentration (Giubbina et al., 2017; Gonçalves et al., 2010).

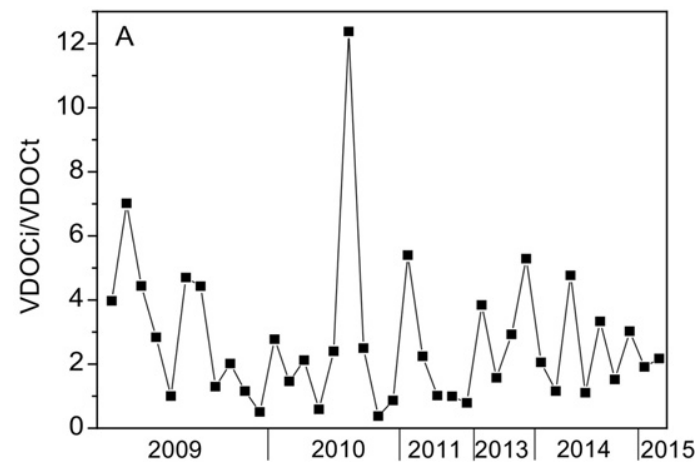

\subsection{Efficiency of atmospheric removal processes}

The efficiencies of removal of atmospheric volatile and dissolved organic carbon during the same rain event were assessed by comparing the concentrations of the organic species at the beginning of the event (i) and for the entire event $(t)$. The ratios between $V_{D O C}$ and $V_{D O C}$ were quite variable and ranged from 0.4 to 12 , indicating an efficient below-cloud scavenging process (Fig. 7). This efficient washout mechanism was in agreement with the findings of Avery et al. (2009) in USA, where significant VDOC concentrations were only found in the first milliliters of rainwater samples. However, in the present work, precipitation as high as $52 \mathrm{~mm}$ still showed significant volatile dissolved organic carbon $\left(29 \mu \mathrm{mol} \mathrm{L} \mathrm{L}^{-1}\right)$. The ratios between $\mathrm{DOC}_{\mathrm{i}}$ and $\mathrm{DOC}_{\mathrm{t}}$ were less variable and ranged from 1.0 to 3.4 , demonstrating the importance of the in-cloud process for removal of organic carbon from the atmosphere.

\subsection{Lability of $D O C$}

The bioavailability of atmospheric organic matter depends on its source. External sources of DOC inputs into the oceans are mainly river water discharges and rainwater deposition (Hansell et al., 2004). In river water, DOC can be very refractory, given the ubiquitous presence of humic substances in this type of environment. In contrast, rainwater DOC can be more bioavailable, since its components include small organic molecules such as carboxylic acids (Avery et al., 2003).

In this work, the DOC in rainwater appeared to be readily labile, as the consumption of organic carbon exceeded $50 \%$ within one week of incubation (Fig. 8A). Such a significant decrease was only observed after a month of incubation of rainwater collected at Wilmington (North Carolina, USA) (Avery et al., 2003). This indicated that there was more intense bacterial activity in the Brazilian samples and/or that the organic matter was more labile (with labile molecules likely to include low molecular weight organic compounds derived from ethanol biofuel). DOC concentrations in surface waters (0-100 m depth) of the South Atlantic Gyre were found to range from 50 to $70 \mu \mathrm{mol} \mathrm{C} \mathrm{L}{ }^{-1}$, highlighting the importance of long distance atmospheric transport of organic carbon to fuel primary productivity (Pan et al., 2014).

For all the samples analyzed in this work, the biodegradation process resulted in the formation of volatile organic compounds, but to different extents (Fig. $8 \mathrm{~B}$ ). Part of the VDOC and $\mathrm{CO}_{2}$ produced during the incubation time could have been lost to the headspace. Despite the substantial variability in initial DOC concentrations and degradation rates, the concentrations of refractory organic compounds were in the range $20-40 \mu \mathrm{mol} \mathrm{L}^{-1}$ for all samples. These concentrations of refractory organic compounds in the Brazilian rainwater samples were close to those found in the USA samples, despite the differences in sources and degradation rates, indicating a common source (Avery et al., 2003).

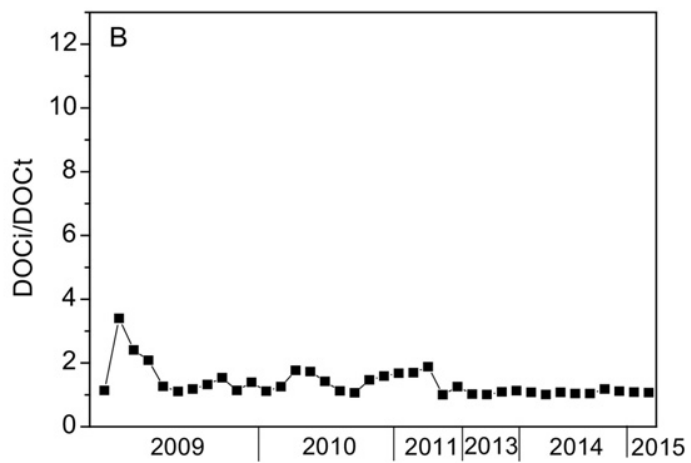

Fig. 7. Ratios between the initial concentrations (i) and overall concentrations (t) of VDOC (A) and DOC (B) in 38 rainwater samples collected in Araraquara. 

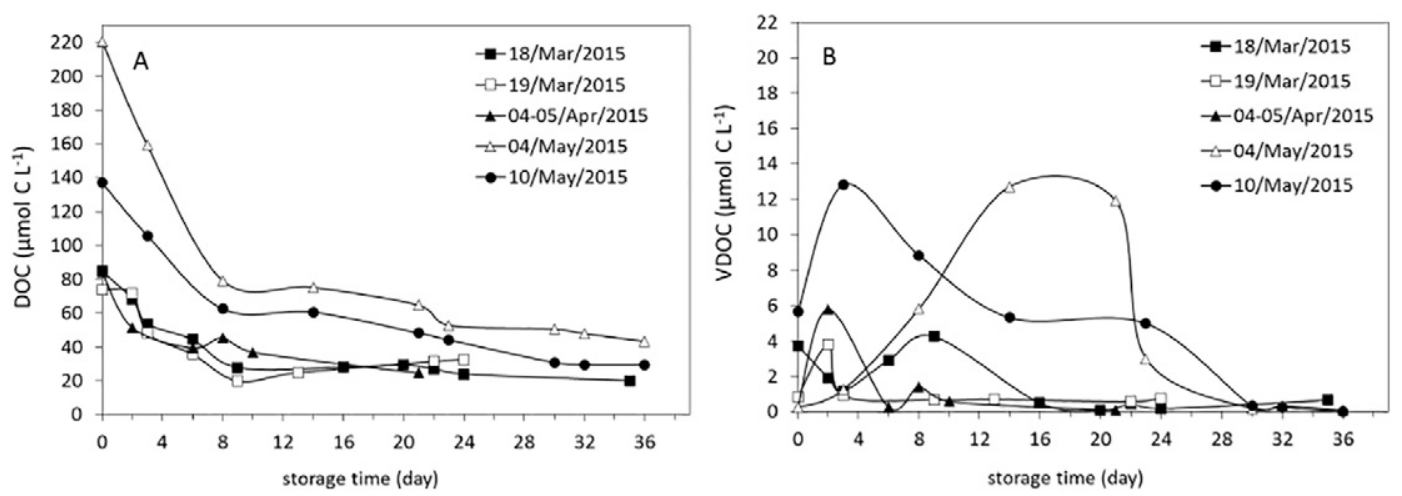

Fig. 8. Temporal changes in (A) DOC and (B) VDOC concentrations in unfiltered rainwater samples incubated at room temperature.

\section{Conclusions}

Although the DOC content in rainwater spanned two orders of magnitude, the annual average concentrations (VWM), and consequently the estimated deposition fluxes, showed little variation during this 13year time series. During this period, the practice of burning sugar cane leaves prior to harvest was gradually phased out. However, substantial numbers of fires (rural burning and wildfires) continued to be detected. We present evidence that biomass burning emissions of soluble organic carbon overwhelm those from fossil fuel combustion and natural biogenic emissions in the study region. Biomass burning can also be responsible for the significant content of volatile organic carbon present in the regional troposphere, leading to health impacts and climate effects that remain poorly understood.

The calculated wet deposition flux of soluble organic carbon exceeded the global estimate by $>40 \%$, showing the need for further assessments in the Southern Hemisphere in order to improve global carbon cycle modeling. Model calculations have indicated a small (or null) global transfer of continental organic carbon to the oceans in the form of wet precipitation. However, the values may have been underestimated, because the DOC concentrations used did not take into account high biomass burning emission sources in tropical countries. The large carbon flux calculated here, added to the effect of longrange transport and the presence of highly bioavailable organic compounds, can lead to an important source of nutrients in the marine environment. The increasing use of ethanol as a vehicular fuel may increase the content of bioavailable low molecular weight organic compounds in rainwater, and consequently their deposition to aquatic ecosystems. In the context of a warming climate, a shallower oceanic mixing layer is likely to increase the impact of atmospheric nutrient deposition inputs to surface waters.

The findings of this work contribute to elucidation of the atmospheric carbon cycle, highlighting the importance of taking account of all the forms in which carbon may be present in rainwater, in order to develop reliable carbon flux models.

\section{Acknowledgements}

The authors are grateful to FAPESP for financial support (research project number 2013/12.789-8), and to CAPES for a PhD grant to D. Godoy-Silva. We are thankful to Dr. A. Setzer from INPE for the productive discussion on the meteorological data.

\section{References}

Anderson, L.G., 2009. Ethanol fuel use in Brazil: air quality impacts. Energy Environ. Sci. 2, 1015-1037.

Avery Jr., G.B., Brown, J.L.D., Willey, J.D., Kieber, R.J., Shank, G.C., Whitehead, R.F., 2003. Flux and bioavailability of cape fear river and rainwater dissolved organic carbon to Long Bay, southeastern United States. Glob. Biogeochem. Cycles 17, 1042-1048.
Avery, G.B., Brown, J.L.D., Willey, J.D., Kieber, R.J., 2009. Assessment of rainwater volatile organic carbon in southeastern north Carolina, USA. Atmos. Environ. 43, 2678-2681.

Boian, C., Kirchhoff, V.W.J.H., 2006. High carbon monoxide concentrations during the rainy season in Campo Grande, in central Brazil. Environ. Pollut. 143, 536-544.

Campos, M.L.A.M., Nogueira, R.F.P., Dametto, P.R., Francisco, J.G., Coelho, C.H., 2007. Dissolved organic carbon in rainwater: glassware decontamination and sample preservation and volatile organic carbon. Atmos. Environ. 41, 8924-8931.

Carey, F.A., 1983. Advanced Organic Chemistry: Structure and Mechanisms. Plenum Press, New York.

CEPAGRI - Centro de Pesquisas Meteorológicas e Climáticas Aplicadas à Agricultura, 2016 Available from:. http://www.cpa.unicamp.br/outras-informacoes/clima-dosmunicipios-paulistas.html (accessed 20.02.17).

Ciglasch, H., Lilienfein, J., Kaiser, K., Wilcke, W., 2004. Dissolved organic matter under native Cerrado and Pinus caribaea plantations in the Brazilian savanna. Biogeochemistry 67, 157-182.

Coelho, C.H., Francisco, J.G., Nogueira, R.F.P., Campos, M.L.A.M., 2008. Dissolved organic carbon in rainwater from areas heavily impacted by sugar cane burning. Atmos. Environ. 42, 7115-7121.

Coelho, C.H., Allen, A.G., Fornaro, A., Orlando, E.A., Grigoletto, T.L.B., Campos, M.L.A.M., 2011. Wet deposition of major ions in a rural area impacted by biomass burning emissions. Atmos. Environ. 45, 5260-5265.

Crutzen, P.J., Andreae, M.O., 1990. Biomass burning in the tropics: impact on atmospheric chemistry and biogeochemical cycles. Science 250, 1669-1678.

FAO - Food And Agriculture Organization Of The United Nations, 2017. Available from: http://www.fao.org/faostat/en/\#data/QC/visualize (accessed 01.06.17).

Félix, J.D., Willey, J.D., Thomas, R.K., Mullaugh, K.M., Avery, G.B., Kieber, R.J., Mead, R.N., Helms, J., Giubbina, F.F., Campos, M.L.A.M., Cala, J., 2017. Removal of atmospheric ethanol by wet deposition. Glob. Biogeochem. Cycles 31. http://dx.doi.org/10.1002/ 2016 GB005516.

Giubbina, F.F., Scaramboni, C., De Martinis, B.S., Godoy-Silva, D., Nogueira, R.F.P., Campos, M.L.A.M., 2017. A simple method for simultaneous determination of acetaldehyde, acetone, methanol, and ethanol in the atmosphere and natural water. Anal. Methods 9, 2915-2922.

Gonçalves, C., Santos, M.A., Fornaro, A., Pedrotti, J.J., 2010. Hydrogen peroxide in the rainwater of Sao Paulo megacity: measurements and controlling factors. J. Braz. Chem. Soc. 21, 331-339.

Hallquist, M., Wenger, J.C., Baltensperger, U., Rudich, Y., Simpson, D., Claeys, M., Dommen, J., Donahue, N.M., George, C., Goldstein, A.H., Hamilton, J.F., Herrmann, H., Hoffmann, T., Iinuma, Y., Jang, M., Jenkin, M.E., Jimenez, J.L., Kiendler-Scharr, A., Maenhaut, W. McFiggans, G., Mentel, Th.F., Monod, A., Prévôt, A.S.H., Seinfeld, J.H., Surratt, J.D. Szmigielski, R., Wildt, J., 2009. The formation, properties and impact of secondary organic aerosol: current and emerging issues. Atmos. Chem. Phys. 9, 5155-5236.

Hansell, D.A., Kadko, D., Bates, N.R., 2004. Degradation of terrigenous dissolved organic carbon in the western Arctic Ocean. Science 304, 858-861.

Hu, G.-P., Balasubramanian, R., 2003. Wet deposition of trace metals in Singapore. Water Air Soil Pollut. 144, 285-300.

Iavorivska, L., Boyer, E.W., DeWalle, D.R., 2016. Atmospheric deposition of organic carbon via precipitation. Atmos. Environ. 146, 153-163.

IBGE - Instituto Brasileiro de Geografia e Estatística, 2016. Available from:. http://www ibge.com.br/cidadesat/topwindow.htm (accessed 20.02.17).

INPE - Instituto Nacional de Pesquisas Espaciais, 2017. Available from:. https://queimadas. dgi.inpe.br/queimadas/estatistica_estados (accessed 20.02.17).

Kanakidou, M., Duce, R.A., Prospero, J.M., Baker, A.R., Benitez-Nelson, C., Dentener, F.J., Hunter, K.A., Liss, P.S., Mahowald, N., Okin, G.S., Sarin, M., Tsigaridis, K., Uematsu, M., Zamora, L.M., Zhu, T., 2012. Atmospheric fluxes of organic N and $\mathrm{P}$ to the global ocean. Glob. Biogeochem. Cycles 26. http://dx.doi.org/10.1029/ 2011GB004277.

Keywood, M., Kanakidou, M., Stohl, A., Dentener, F., Grassi, G., Meyer, C.P., Torseth, K., Edwards, D., Thompson, A.M., Lohmann, U., Burrows, J., 2013. Fire in the air: biomass burning impacts in changing climate. Crit. Rev. Environ. Sci. Technol. 43, 40-83.

Kieber, R.J., Peake, B., Willey, J.D., Avery, G.B., 2002. Dissolved organic carbon and organic acids in coastal New Zealand rainwater. Atmos. Environ. 36, 3557-3563.

Miller, J.N., Miller, J.C., 2010. Calibration Methods in Instrumental Analysis: Regression and Correlation. sixth ed. Pearson Education Limited, Gosport. 
Mopper, K., Kieber, R.J., 1990. Determination of picomolar concentrations of carbonyl compounds in natural waters, including seawater, by liquid chromatography. Environ. Sci. Technol. 24, 1477-1481.

Mullaugh, K.M., Kieber, R.J., Willey, J.D., Avery, G.B., 2011. Long-term temporal variability in hydrogen peroxide concentrations in Wilmington, North Carolina USA rainwater. Environ. Sci. Technol. 45, 9538-9542.

NOAA - National Oceanic and Atmospheric Administration, 2017. Avaible from:. http:// www.ready.noaa.gov/hypub-bin/trajasrc.pl (accessed 05.01.17).

Pan, X., Achterberg, E.P., Sanders, R., Poulton, A.J., Oliver, K.I.C., Robinson, C., 2014. Dissolved organic carbon and apparent oxygen utilization in the Atlantic Ocean. DeepSea Res. I 85, 80-87.

Raymond, P.A., 2005. The composition and transport of organic carbon in rainfall: insights from the natural $\left({ }^{13} \mathrm{C}\right.$ and $\left.{ }^{14} \mathrm{C}\right)$ isotopes of carbon. Geophys. Res. Lett. 32. http://dx. doi.org/10.1029/2005GL022879.

Scaramboni, C., Urban, R.C., Lima-Souza, M., Nogueira, R.F.P., Cardoso, A.A., Allen, A.G. Campos, M.L.A.M., 2015. Total sugars in atmospheric aerosols: an alternative tracer for biomass burning. Atmos. Environ. 100, 185-192.

SMA - Secretaria do Meio Ambiente, 2016. Available from:. http://www.ambiente.sp.gov.br/ 2016/04/28/protocolo-agroambiental-do-setor-sucroenergetico-263-da-areaagricultavel-de-sao-paulo-esta-comprometida-com-boas-praticas/ (accessed 31.05.17).

Souza, M.L., Allen, A.G., Cardoso, A.A., 2017. Understanding aerosol formation mechanisms in a subtropical atmosphere impacted by biomass burning and agroindustry. Atmos. Res. 183, 94-103.
Tsigaridis, K., Kanakidou, M., 2003. Global modeling of secondary organic aerosol in the troposphere: a sensitivity analysis. Atmos. Chem. Phys. 3, 1849-1869.

UNICA - União da Indústria de Cana-de-Açúcar, 2016. Available from:. http://www. unicadata.com.br (accessed 01.06.17).

Urban, R.C., Lima-Souza, M., Caetano-Silva, L., Queiroz, M.E.C., Nogueira, R.F.P., Allen, A.G., Cardoso, A.A., Held, G., Campos, M.L.A.M., 2012. Use of levoglucosan, potassium, and water-soluble organic carbon to characterize the origins of biomass-burning aerosols. Atmos. Environ. 61, 562-569.

Urban, R.C., Alves, C.A., Allen, A.G., Cardoso, A.A., Campos, M.L.A.M., 2014. Sugar markers in aerosol particles from an agro-industrial region in Brazil. Atmos. Environ. 90, 106-112.

Urban, R.C., Alves, C.A., Allen, A.G., Cardoso, A.A., Campos, M.L.A.M., 2016. Organic aerosols in a Brazilian agro-industrial area: speciation and impact of biomass burning. Atmos. Res. 169, 271-279.

Wang, X, Ge, T, Xu, C, Xue, Y, Luo, C, 2016. Carbon isotopic $\left({ }^{14} \mathrm{C}\right.$ and $\left.{ }^{13} \mathrm{C}\right)$ characterization of fossil-fuel derived dissolved organic carbon in wet precipitation in Shandong Province, China. J. Atmos. Chem. 73, 207-221.

Williams, M.R., Fischer, T.R., Melack, J.M., 1997. Chemical composition and deposition of rain in the Central Amazon, Brazil. Atmos. Environ. 31, 207-217. 